ISSN 2693-2504

\title{
Coagulation Tests' Normal Values in a Cameroonian Adult Population
}

\section{Journal of Bioscience \& Biomedical Engineering}

\begin{abstract}
V M Ngounou ${ }^{1,2}$, P Angandji $^{1^{*}}$, A Ndoumba ${ }^{1,3}$, CT Tagny ${ }^{1,3}$ and D Mbanya ${ }^{1,3}$
${ }^{1}$ Haematology and Blood Transfusion Service, Yaounde University Teaching Hospital, Cameroon

${ }^{2}$ School of Health Sciences/Catholic University of Central Africa, Yaounde, Cameroon

*Correspondence author

Prisca ANGANDJ, MD

Clinical Biologist

Cameroon

${ }^{3}$ Department of Haematology, Faculty of Medicine and Biomedical Sciences, University of Yaounde, Cameroon

Submitted : 6 Dec 2020 ; Published : 6 Jan 2021

Abstract

Coagulation tests are routine analyses most prescribed in routine medical practices. Africans tend to use the thresholds of other races since they don't have their own normal values.

This was a prospective descriptive study carried out at the Yaounde University Teaching Hospital to determine normal values for coagulation's tests. We included 160 venous samples from healthy blood donors, aged 18 to 56 years. Standard techniques were used for the measurement of prothrombin time, activated partial thromboplastin time and fibrinogen levels in all samples. The median prothrombin time was $13.01 \mathrm{~s}$ (10.2.-15.2) with a significant difference between males $(P T=13,2 s(11,1-15,5))$ and females $(P T=13,0 s(10,1-15,2)), p=0,02$ but not significant between the age groups $(p=0,31)$. The median of APTT and fibrinogen were $32.4 s(22.2 .-40.5), 2.8 \mathrm{~g} / \mathrm{L}$ (1.5-4.2) and not significant between sex and age groups, $p=0,34$ and 0,14 respectively. Although the sample size does not allow for generalized conclusions, nevertheless, these findings provide indications to normal ranges for these coagulation tests among healthy adult Cameroonians. Furthermore, it may be relevant to consider the gender when interpreting coagulation tests in Cameroonian settings.
\end{abstract}

Keywords: Coagulation, Cameroonian Adult Population, Normal Values

Abbreviations:

APTT : Activated Partial Thromboplastin Time;

$\mathrm{g} / \mathrm{L} \quad$ : grams per liter;

s : Seconds;

PT : Prothrombin Time.

\section{Introduction}

Prothrombin time (PT) is a test used in extrinsic coagulation pathway evaluation [1]. Developed by Quick and al in 1935, it consists in adding calcium and tissue thromboplastin to citrated plasma to activate the clotting cascade. PT is used for the diagnosis of coagulation disorders, monitoring of patients under oral anticoagulant drugs and evaluating the liver functions. PT is the one of the most commonly used coagulation test in routine laboratories.

Activated Partial Thromboplastin Time (APTT) is a test for the intrinsic and common pathways, used for the screening of factors II, V, VIII, IX, X, XI and XII deficiencies.

Fibrinogen or factor I of the coagulation cascade is a glycoprotein secreted into the blood of vertebrates by liver cells. During tissue and vascular injury it is converted enzymatically by thrombin to fibrin and subsequently to a fibrin-based clot. It functions to occlude blood vessels and thereby stop excessive bleeding.

Values of those three coagulation tests used in Cameroonian laboratories are those of the literature determined on caucasian populations and from the fabricants. They were determined on a caucasian population. Although studies in different contexts $[2,3]$ reported means significant differences of these coagulation tests between Caucasian and African subjects according to gender, race, diet, local population, analytical methods, procedures and environment, the Cameroonian Reference Center for Hemophilia usually applies the manufacturer's reference ranges rather than its own reference ranges.

Since there are no reports on normal values for coagulation at the Hemophilia Treatment Centre (HTC), we aimed at determining ranges for PT, APTT and fibrinogen levels in healthy blood donors and to compare them with those found in the literature.

\section{Methods}

The study was carried out at the Hematology Laboratory of the Hematology and Blood Transfusion Service of the University Teaching Hospital in Yaounde over a period of 7 months, from october 2016 to aril 2017. This service is directed by 
three physicians: a Professor of Hematology assisted by an Associate Professor and a Senior Lecturer of Hematology. Eight medico-sanitary technicians constitute the other members of the staff. Frequently, there are residents (medical doctors in specialization), and other technicians in training in the service for internships.

HTC is located in the Hematology Laboratory of the University Teaching Hospital in Yaounde. Daily activities consist in the diagnosis of hemophilia which is a disorder caused by the lack of coagulation factors, mainly factors VIII and IX. The study population consisted of blood donors in good health, without any coagulation/clotting problems, and who gave their consent to participate. Good health was defined as the absence of each of the four diseases markers (HIV, hepatitis B, hepatitis $\mathrm{C}$ and syphilis) tested at the blood transfusion unit, and the hemoglobin levels of at least at $12 \mathrm{~g} / \mathrm{dL}$ for women and $13 \mathrm{~g} /$ $\mathrm{dL}$ for men.

With the aid of a pre-conceived data-collection form, demographic (age, sex) and hemostatic parameters (PT, APTT, fibrinogen levels) of each subject were recorded. Blood donors were classified according to the regions of their origin into three (Bantous: From Center, South, East and Littoral regions; Semi-Bantous: From West, North-West, South-West regions; Sudanese: From Adamaoua, North and Far-North regions). For each subject, one venous blood sample was collected into a citrated tube and was used for coagulation tests (PT, APTT, fibrinogen levels). The samples were centrifuged at 1200 rpm for 15 minutes to obtain platelet-poor plasma, which was introduced into a Stago START 4 coagulation analyzer, version 2002, (France), for coagulation tests. Thromboplastin (Neoplastin ${ }^{\circledR}$ ) used for measurement of prothrombin time and fibrinogen (Fibrinogène ${ }^{\circledR}$ ) were obtained from Cypress Diagnostics (Belgium) while C.K. Prest ${ }^{\circledR}$ was used for the measurement of APTT (supplied by Stago, France). All coagulation tests were done in duplicates for each plasma sample within a period of two to four hours following blood collection. Results were expressed in terms of means (in second) for PT and APTT. Fibrinogen levels were measured in grams per liter $(\mathrm{g} / \mathrm{L})$.

The data were entered using Epi-Info version 7 and then cleaned and analysed using the SPSS version 20 software package. Data cleaning was carried out by running frequency of each categorical variable and cross tabulation of different categorical variables. Descriptive results were summarized as percentage. Medians and standard deviations were compared using ANOVA tests. The Student T test enabled us to compare subgroups two-by-two. A p value of less than 0.05 was considered as statistically significant quantitative variables were analyzed as continuous variables. Descriptive analysis of differences between demographic and coagulation parameters between the subgroups was also carried out.

The research was conducted after obtaining ethical approval from the Research and Ethical Committee of School of Health Sciences and the administrative authorities of the Yaounde University Teaching Hospital. In addition, after explaining the importance of the study, an informed consent was obtained from each study participant.

\section{Results}

One hundred and sixty blood samples were collected from blood donors aged 18 to 55 years predominantly the Bantous' group. The youngest aged group was the most represented. Sex ratio was 0,97 .(Table 1$)$.

\begin{tabular}{|l|l|l|}
\hline Parameters & Frequencies & Percentage (\%) \\
\hline Age (years) & 55 & 34,4 \\
\hline$[18-26]$ & 53 & 33,1 \\
\hline$[26-36]$ & 52 & 32,5 \\
\hline$[36-56]$ & \multicolumn{2}{|l|}{} \\
\hline Sex & 79 & 49,4 \\
\hline Male & 81 & 50,6 \\
\hline Female & \multicolumn{2}{|l|}{} \\
\hline Ethnic groups & 96 & 60 \\
\hline Bantous & 64 & 40 \\
\hline Semi-Bantous & 00 & 00 \\
\hline Sudanese & 160 & 100 \\
\hline TOTAL & &
\end{tabular}

Table 1: Socio-demographic characteristics of a hundred and sixty blood donors at the Hematology Laboratory and Blood Transfusion Service of the Yaounde University Teaching Hospital, 2017.

Bantous: From Center, South, East and Littoral regions SemiBantous: From West, North-West, South-West regions Sudanese: From Adamawa, North and Far-North regions

The median prothrombin time and APTT in the studied population were $13,01(10,2-15,2)$ seconds and 32,4 (22,2$40,5)$ seconds respectively. $2,8(1,5-4,2) \mathrm{g} / \mathrm{L}$ was the median fibrinogen value in the whole population (Table 2). 


\begin{tabular}{|c|c|c|c|c|c|c|c|}
\hline \multirow{2}{*}{$\begin{array}{l}\text { COAGULATION } \\
\text { TESTS' }\end{array}$} & & \multirow{2}{*}{$\begin{array}{l}\text { All population } \\
N=160\end{array}$} & \multicolumn{3}{|l|}{ Age groups } & \multicolumn{2}{|l|}{ Sex } \\
\hline & & & {$[18-26] N=55$} & {$[26-36] \mathrm{N}=53$} & {$[36-56] N=52$} & Male $\mathrm{N}=79$ & Female $\mathrm{N}=81$ \\
\hline \multirow[t]{3}{*}{ PT } & Median & 13,01 & 13,5 & 12,9 & 13,0 & 13,2 & 13,0 \\
\hline & Range & $10,2-15,2$ & $11,4-15,9$ & $9,6-15,6$ & $10,4-15,6$ & $11,1-15,5$ & $10,1-15,2$ \\
\hline & $\mathrm{P}$ & & \multicolumn{3}{|l|}{0,31} & \multicolumn{2}{|l|}{0,02} \\
\hline \multirow[t]{3}{*}{ APTT } & Median & 32,4 & 31,6 & 31,5 & 33,5 & 33,2 & 32,3 \\
\hline & Range & $22,2-40,5$ & $22,1-43,5$ & $23,4-41,6$ & $20,8-41,7$ & $25,7-42,3$ & $20,7-40,5$ \\
\hline & $\mathrm{P}$ & & 0,11 & & & 0,14 & \\
\hline \multirow[t]{3}{*}{ FIBRINOGEN } & Median & 2,8 & 2,9 & 2,7 & 2,9 & 2,7 & 2,9 \\
\hline & Range & $1,5-4,2$ & $1,3-4,5$ & $1,7-4,2$ & $1,6-4,4$ & $1,5-4,4$ & $1,6-4,2$ \\
\hline & $\mathrm{P}$ & & \multicolumn{3}{|l|}{0,22} & \multicolumn{2}{|l|}{0,34} \\
\hline
\end{tabular}

Table 2: Means of coagulation parameters in a hundred and sixty blood donors at the Hematology laboratory and Blood Transfusion Service of the Yaounde University Teaching Hospital, 2017.

The median prothrombin time was significantly different between males and females $(\mathrm{p}=0,02)$. The median APTT and fibrinogen were respectively $32.4(22.2 .-40.5) \mathrm{s}, 2.8(1.5-4.2)$ $\mathrm{g} / \mathrm{L}$ and not significant between sex and ages' groups, $\mathrm{p}=0,34$ and 0,14 respectively(Table 2 ).

The median prothrombin time and APTT obtained are different from the results in France but for fibrinogen, they are almost similar (Table 3).

\begin{tabular}{|c|c|c|c|}
\hline \multirow[t]{2}{*}{ Parameters } & \multirow{2}{*}{$\begin{array}{l}\text { This study, } \\
2017 \\
\text { Cameroon }\end{array}$} & \multicolumn{2}{|l|}{ Literature } \\
\hline & & $\begin{array}{l}\text { Steve } \\
\text { Kitchen }^{6} \text { and } \\
\text { coll., } 2010 \\
\text { WFH }\end{array}$ & $\begin{array}{l}\text { Guido }^{7} \text { and } \\
\text { Boehlen, } \\
2008 \\
\text { Switzerland }\end{array}$ \\
\hline PT (in s) & $10,2-15,2$ & ID & $11,3-13,6$ \\
\hline APTT (in s) & $22,2-40,5$ & $24-36$ & $27-35$ \\
\hline $\begin{array}{l}\text { FIBRINOGEN( } \\
\text { in } \\
\mathrm{g} / \mathrm{L})\end{array}$ & $1,5-4,2$ & $2-4$ & $1,7-3,3$ \\
\hline
\end{tabular}

Table 3: Comparative coagulation's usual values of a hundred and sixty blood donors at the hematology laboratory and blood bank of the University Teaching Hospital, 2017 and those of the literature.

ID: In determined g/L: grams per Liter s: seconds WFH: World Federation of Hemophilia

\section{Discussion}

Reference intervals are useful for clinical decisions, including diagnosis and patients' management. Routine coagulation parameters such as PT, APTT and fibrinogen have widely been studied in Caucasian but SubSaharan Africa has no reference intervals. This study provides reference intervals for PT, aPTT and fibrinogen in healthy adults in Cameroon.

One hundred and sixty blood donors were recruited. According to the International Federation of Hemophilia [4], one hundred and twenty samples are enough to establish reference values. The Bantous group mostly represented for blood donation could be due to the fact that the study was done in Yaounde,
Cameroon in the Center Region where the tribes constituting this group mostly live.

The median prothrombin time significantly differed from male to female as also reported by Abdullah S. et al [5]. This suggests that gender has an impact on coagulation and normal values should be given according to gender.

Prothrombin time, activated PTT and Fibrinogen ranges found in our study are different from the ranges reported by many authors $[6,7]$. These differences should be due to race, diet and environment [8] as it has been shown earlier. Other authors [9] reported that normal range of PT depends on the reagents used. Some also reported that this intervariability could be due to the instrument used to analyse PT [10].

Lastly, the range of PT is higher in our study than from Eberhard $\mathrm{W}$ et al [11]. We collected blood samples and analysed them in glass tubes. This last author [11] showed that PT plastic tubes are decreased than those obtained in glass tubes. The type of tube can affect PT and INR results at a clinically relevant level.

\section{Limitations}

We recognize one limitation in this study that our evaluation of coagulation tests was only done in one of the ten Regions of Cameroon; nevertheless, the results obtained would serve as guide in all laboratories in Cameroon.

\section{Conclusion}

Our findings provide a basis for normal ranges in coagulation tests in adult Cameroonians. It would be more accurate to take into account the gender while interpreting prothrombin time in clinical practice.

\section{References}

1. Avwioro OG, Ezeobi JO, Oduola T, Fakunle OO (2013) Prothrombin time and Activated Partial Thromboplastin time in Pregnant Women in Southern Nigeria. Journal of Applied Pharmaceutical Science, Vol. 6(3).

2. Eunjung Lim; Jill Miyamura PhD; and John J Chen (2015) Racial/Ethnic-Specific Reference Intervals for Common 
Laboratory Tests: A comparison among Asians, Blacks, Hispanics and White. Hawai Journal of Medicine \& Public Health vol 74(9).

3. Njikeutchi Françoise (2003) Contribution to the establishment of reference values for biological parameters in adult Burbinabè: Evaluation of five biochemical constituents at the biology chemistry department of the Yalgado Ouédraogo National Hospital Center (C.H.N.Y.O) in Ouagadougou. Thesis for obtaining the degree of doctor of pharmacy, UNIVERSITE DE OUAGADOUGOU.

4. Clinical and laboratory standards institute (2000) How to Define and Determine Reference Intervals in the Clinical Laboratory; Approved Guideline Second Edition, Pennsylvania, C28A2, 2000.

5. Abdullah Sivrikaya, Hatice Haran, Bahadir ÖzlÜrk, HÜsamettin Vatanser (2013) Effect of gender and age on prothrombin time, activated partial thromboplastin levels and INR. IJMMS 1(2): 27-29.

6. Steve kitchen, Angus $\mathrm{McCr}$ aw, Marion Echenagucia (2010) Diagnosis of Hemophilia and other bleeding disorders. A Laboratory Manual, Second Edition. World Federation of Hémophilia, 2010

7. Guido, Reber, Françoise, Boehlen (2008) angiologie hémostase Rev Med Suisse; 350-353.

8. Lutsey PL, Cushman M, Steffen LM, Green D, Barr RG, Herrington D, Outang P, Folsom AR (2006) Plasma hemostatic factors and endothelial markers in four racial/ ethnic groups: the MESA study. J Thromb Haemost 26292635.

9. Pagana KD, Pagana TJ, Pagana TN (2019) Mosby's Diagnostic and Laboratory Test Reference. $14^{\text {th }}$ ed. St Louis, Mo:Elsevier, 2019.

10. Sherilyn Alvaran (2019) PT with interlaboratory variability ingluenced by the instrument and the reagent used. Drugs and Diseases, Nov 21,2019.

11. Eberwhald W. Fiebig (2005) clinicall Relevant differences in PT and INR values Related to Blood Sample Collection in Plastic vs Glass Tubes. Am J Clin Pathol 124: 902-909.

Copyright: (O2021 Prisca ANGANDJI. This is an open-access article distributed under the terms of the Creative Commons Attribution License, which permits unrestricted use, distribution, and reproduction in anymedium, provided the original author and source are credited. 